\title{
Toxicity of essential oils to slug parasitic and entomopathogenic nematodes
}

\author{
Archita Barua $^{1} \cdot$ Kerry-Lyn McDonald-Howard ${ }^{1} \cdot$ Rory J. Mc Donnell $^{2} \cdot$ Robbie Rae $^{1} \cdot$ Christopher D. Williams $^{1}$
}

Received: 23 December 2019 / Revised: 12 May 2020 / Accepted: 6 June 2020 / Published online: 15 June 2020

(c) The Author(s) 2020

\begin{abstract}
Essential oils are being increasingly utilised as a biorational element in integrated pest management regimes. Whereas there has been much research on the effects of these oils on mortality and behaviour of pestiferous molluscs, insects and nematodes, there has (to the present authors' knowledge) been no research into their effects on the mortality and behaviour of beneficial nematodes. We address this lacuna by conducting laboratory assays on the behaviour (thrashing assays) and mortality of 13 essential oils plus controls of Tween and water on the malacophagous nematode Phasmarhabditis hermaphrodita and two species of entomopathogenic nematodes, namely: Steinernema feltiae and Heterorhabditis bacteriophora. Mortality results showed an "all or nothing" response with only three oils—pine oil, peppermint and lemongrass—displaying intermediate mortalities. Also, toxicity of essential oils was conserved across phylogenetically quite distinct beneficial nematode species with oil toxicity largely being repeated across the three beneficial nematodes. Thrashing assays confirmed the toxic effects of certain oils. We recommend that the effects of essential oils be tested on beneficial organisms in ecosystems before choices are made over which oils should be used. The present paper highlights some oils which are not toxic to beneficial nematodes but may affect their behaviour. Research should focus on these oils as part of a biorational control programme for pestiferous molluscs and insects.
\end{abstract}

Keywords Essential oils · Entomopathogenic nematodes $\cdot$ Gastropod parasitic nematode $\cdot$ IPM $\cdot$ Biorational control

\section{KeyMessage}

Communicated by M.B. Isman.

Christopher D. Williams

C.D.Williams@ljmu.ac.uk

Archita Barua

a.barua@ljmu.ac.uk

Kerry-Lyn McDonald-Howard

K.McDonaldHoward@2018.ljmu.ac.uk

Rory J. Mc Donnell

rory.mcdonnell@oregonstate.edu

Robbie Rae

R.G.Rae@ljmu.ac.uk

1 School of Biological and Environmental Sciences, Liverpool John Moores University, L3 3AF, Liverpool, UK

2 Department of Crop and Soil, ScienceOregon State University, Corvallis, OR 97331, USA
- Essential oils (EOs) are being increasingly utilised as an element in integrated pest management regimes.

- The majority of studies have predominantly tested the impact of EOs on harmful nematodes only.

- We investigate the effect of thirteen EOs on the mortality and behaviour of beneficial nematodes. The EOs showed an "all or nothing" response on the beneficial nematode species with only a small number of oils showing intermediate mortalities.

- EOs should be tested on various beneficial organisms before they are recommended for use in pest management. 


\section{Introduction}

Indiscriminate and overuse of chemicals for controlling pests and plant diseases for higher yield have developed some negative effects on the environment and led to several problems including pesticide resistance, environmental contamination, destruction of nontarget organisms and pest resurgence (Van der Werf 1996; Bailey 2002). The harmful effects of synthetic chemicals on the environment, humans and animal health have prompted scientists to look for alternative control methods, which are more sustainable and less toxic to the environment. In this aspect, essential oils (EOs) have been gaining prominence as a new class of ecological product with antimicrobial, insecticidal, molluscicidal and nematicidal activity (Ejechi et al. 1999; Isman 2000; Barbosa et al. 2010; Klein et al. 2020). The exemption of many EOs from pesticide registrations and residue tolerance requirements under federal law in the USA (Sect. 25(b) of the Federal Insecticide, Fungicide, and Rodenticide Act) shows that certain oils are non-toxic to humans and can be used as alternatives to synthetic chemicals in agriculture.

EOs are plant-derived products, lipophilic in nature and possess the capacity to hinder metabolic, biochemical, physiological and behavioural functions of insects (Brattsten 1983; Tripathi et al. 2009; Mossa 2016). Research findings show that different constituents of EOs, such as terpenes, alcohols, aldehydes, ethers, ketones, phenols and oxides (Boire et al. 2013), are effective against various pests including insects, mites, fungi, slugs, snails and nematodes (Isman 2000; Mc Donnell et al. 2016; Barua et al. 2017; Klein et al. 2020). In animal phyla, Nematoda is the second most diverse phylum after arthropods living in a wide range of habitats. Usually, nematodes are acknowledged as harmful organisms that cause diseases in economically important crops and parasitise many vertebrates, including humans. However, there also exists beneficial nematodes which have been formulated into biological control agents for combatting insects in farms and gardens (e.g. Steinernema feltiae and Heterorhabditis bacteriophora) and pestiferous gastropods (e.g. Phasmarhabditis hermaphrodita) (Rae et al. 2007; Askary 2010; Coupland et al. 2017). The main attributes of using nematodes for pest control are-nematodes possess a short life cycle and wide host range; they are environmentally safe; and they show persistence even under unfavourable conditions (Askary 2010). Entomopathogenic nematodes (EPN) are obligate parasites of a range of insect species, which utilise symbiotic bacteria (Xenorhabdus for Steinernema and Photorhabdus for Heterorhabditis) to infect and kill insect hosts (Ansari et al. 2003). Phasmarhabditis hermaphrodita is a facultative parasite of slugs and snails that is naturally present in the soil and is able to complete its life on decaying matter, e.g. dead slugs and leaf litter (MacMillan et al. 2009). It has been formulated into a biological control agent (Nemaslug $®$ ) used by farmers and gardeners to kill pestiferous slugs and snails (Rae et al. 2007).

To date, studies that have been conducted on nematodes using EOs have primarily focused on disease-causing parasitic or harmful nematodes. For instance, a variety of EOs extracted from different plant families such as Lamiaceae, Asteraceae, Myrtaceae, Lauraceae and Poaceae have been widely studied for nematicidal activity against pinewood nematode Bursaphelenchus xylophilus and root-knot nematodes Meloidogyne spp. Oka et al. (2000) studied the nematicidal effect of EOs and the active compounds from 27 plant species on the root-knot nematode Meloidogyne javanica at a concentration of $1000 \mu \mathrm{l} /$ litre. Their results reveal that 12 EOs from Poaceae, Lamiaceae, Asteraceae and Apiaceae immobilised more than $80 \%$ of second-stage juveniles (J2). The same study also observed that EOs from eight plants (Artemisia judaica, Carum carvi, Foeniculum vulgare, Mentha rotundifolia, Mentha spicata, Micromeria fruticose, Origanum syriacum and Origanum vulgare) cause reduction in egg hatching ( $<5 \%$ ) of Meloidogyne javanica. Perez et al. (2003) demonstrated that the EO of Chrysanthemum coronarium (at 2, 4, 8 and $16 \mu \mathrm{l} / \mathrm{ml}$ ) significantly reduced egg hatching, $\mathrm{J} 2$ survival and reproduction rate of Meloidogyne artiellia. On the other hand, Ntalli et al. (2011) analysed the nematicidal activity and synergistic and antagonistic interactions between active components of EOs obtained from seven aromatic species namely Eucalyptus melliodora, Juglans regia, Laurus nobilis, Pistacia terebinthus, Foeniculum vulgare, Pimpinella anisum and Achillea millefolium against Meloidogyne incognita, showing that combinations of nematicidal EO components, such as carvacrol/thymol or carvacrol/geraniol had synergistic activity on $M$. incognita J2 juvenile paralysis. Likewise, Sangwan et al. (1990) evaluated the nematicidal activity of the EOs of different plant species belonging to the families Labiatae, Myrtaceae and Gramineae and their major monoterpenoidal constituents, linalool, eugenol, menthol, cineole and geraniol on four nematode species viz. second stage juveniles of seed gall nematode (Anguina tritici), citrus nematode (Tylenchulus semipenetrans), root knot nematode (Meloidogyne javanica) and pigeon pea cyst nematode (Heterodera cajani).

Whereas there has been much research on the effects of EOs on the mortality and behaviour of pestiferous molluscs, insects and nematodes, there has (to the present authors' knowledge) been no research into their effects on the mortality and behaviour of beneficial nematodes such as EPN and slug-parasitic nematodes. We address this research lacuna by assessing the impact of 13 EOs in laboratory assays on the behaviour (thrashing assays) and mortality 
of $P$. hermaphrodita and two species of entomopathogenic nematodes (EPN), namely: S. feltiae and H. bacteriophora.

\section{Materials and methods}

\section{Source of nematodes and EOs}

The commercial strain of P. hermaphrodita (Nemaslug®), H. bacteriophora and S. feltiae (Nemasys ${ }^{\circledR}$ ) were purchased from BASF Becker Underwood Agricultural Specialities. Prior to use, all products were stored at $10{ }^{\circ} \mathrm{C}$ in the laboratory. Thirteen EOs (Birch tar [Betula alba], Bitter Orange [Citrus bigaradia, C. amara], Cedarwood [Juniperus virginiana], Cinnamon [Cinnamomum cassia], Clove [Eugenia caryophyllata], Eucalyptus [Eucalyptus globulous], Garlic [Allium sativum], Lemongrass [Cymbopogon citrates], Spearmint [Mentha spicata], Peppermint [Mentha piperita], Pine [Pinus strobes], Rosemary [Rosmarinus officinalis] and Thyme [Thymus vulgaris]) were used for studying the survival and thrashing of the three nematode species. The reason behind selection of above-mentioned oils is that most of the oils have been tested for molluscicidal, insecticidal and acaricidal activity in other studies (Mc Donnell et al. 2016; Rios et al. 2017; Barua et al. 2017; Klein et al. 2020). All the oils were procured from https://www.essentialoil.com except Birch Tar, which was ordered from https://www.pipingrock .com/essential-oils-mc.

\section{Effect of EOs on survival of nematodes}

To study the effect of EOs on the survival of nematodes, an oil solution was made following the method prescribed by Mc Donnell et al. (2016). The oil solution was used in emulsion form by first mixing the EO with Tween 80 in a ratio of 1:2. Tween 80 was used as an emulsifier. The nematodes were mixed with water, quantified and 10-15 nematodes were added in $25 \mu \mathrm{l}$ of water to $1 \%$ concentration of EO solution (e.g. $10 \mu \mathrm{l}$ oil and Tween mixer in $25 \mu \mathrm{l}$ nematode suspension and $965 \mu \mathrm{l}$ water) which was used for the survival study. Tween solution at $2 \%$ and tap water were used as control. Although 1\% is towards the high end of concentrations of EOs, the product Snail \& Slug Away® contains $1.35 \%$ cinnamon oil as the active ingredient. Also, $1 \%$ has been used in the published literature to screen for molluscicidal activity (see Mc Donnell et al. 2016; Klein et al. 2020). The oil solutions and control were added to 5 separate wells in a 96 well plate. To each well, a single dauer juvenile of $P$. hermaphrodita, $S$. feltiae and $H$. bacteriophora were added separately. A lid was placed on the 96 well plate; sealed with Parafilm ${ }^{\circledR}$ and then incubated at $20^{\circ} \mathrm{C}$ for four days. To confirm the lethal effect the EOs had on nematodes, the treatment solutions were removed after four days and distilled water was added to each well immediately, and the number of mobile and immobile juveniles were counted. Each nematode was prodded with a pick and observed under the microscope for five minutes to verify whether it was alive (bending body) or dead (extended floating body). The experiment was repeated three times for each nematode species.

\section{The effect of EOs on thrashing behaviour of nematodes}

To observe whether the application of EOs has any significant effect on nematodes mobility, a thrashing assay was conducted following the method of Sleigh (2010). A thrashing assay is a well-established method for measuring the frequency of lateral swimming of parasitic nematodes in a liquid medium (Buckingham and Sattelle 2009) and has previously been used as an index to understand the effects of drugs, chemicals and mutations on the motility of nematodes (Buckingham and Sattelle 2009).

A freshly prepared mixture of nematode juveniles and oil solutions ( $1 \%$ concentration) was added to three separate wells in a 24 well plate to allow free movement of the nematodes. Each well contained $60 \mu \mathrm{l}$ of oil emulsion and a nematode suspension (approximately 60 to 70 nematodes). The number of thrashes for three randomly selected nematodes was counted from each well at four different time intervals, i.e. $0 \mathrm{~s}, 15 \mathrm{~min}, 30 \mathrm{~min}$ and $60 \mathrm{~min}$ for $60 \mathrm{~s}$. Each experiment with the oil mixtures, Tween and water was replicated three times for the thrashing assay ( $n=9$ nematodes).

\section{Statistical analysis}

The number of thrashes per minute by each individual nematode species exposed to oil solutions, Tween and water was compared using a two-way ANOVA with a Tukey post hoc test. From the observed juvenile mortality, corrected percent mortality was calculated by using Abbotts formula (Abbott, 1925). No further transformations of the data (e.g. angular transformation) were performed. The measurement of difference was determined according to Tukey's multiple comparison test.

\section{Results}

\section{Nematicidal activity of the EOs}

The mortality rates of $S$. feltiae, $H$. bacteriophora and $P$. hermaphrodita dauer juveniles with different EO treatments are summarised in Fig. 1. The results showed that thyme, cinnamon, clove and garlic oil were highly toxic at $1 \%$ and caused $100 \%$ mortality in all three nematode 
Fig. 1 Percent mortality of $H$. bacteriophora a, S. feltiae $\mathbf{b}$ and $P$. hermaphrodita $\mathbf{c}$ juveniles in $1 \%$ concentration of selected EO emulsions, Tween 80 control and water control $(n \pm S E)$. Means followed by the same letter for each oil do not differ significantly at $p=0.05$ according to Tukey's multiple comparison test

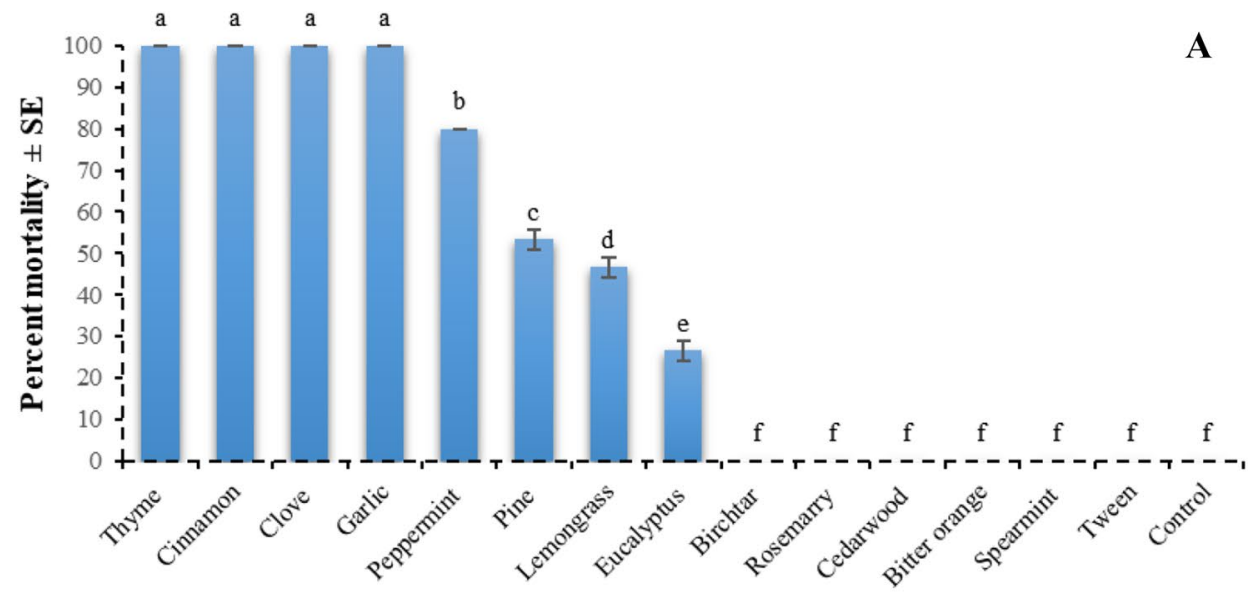

Treatments
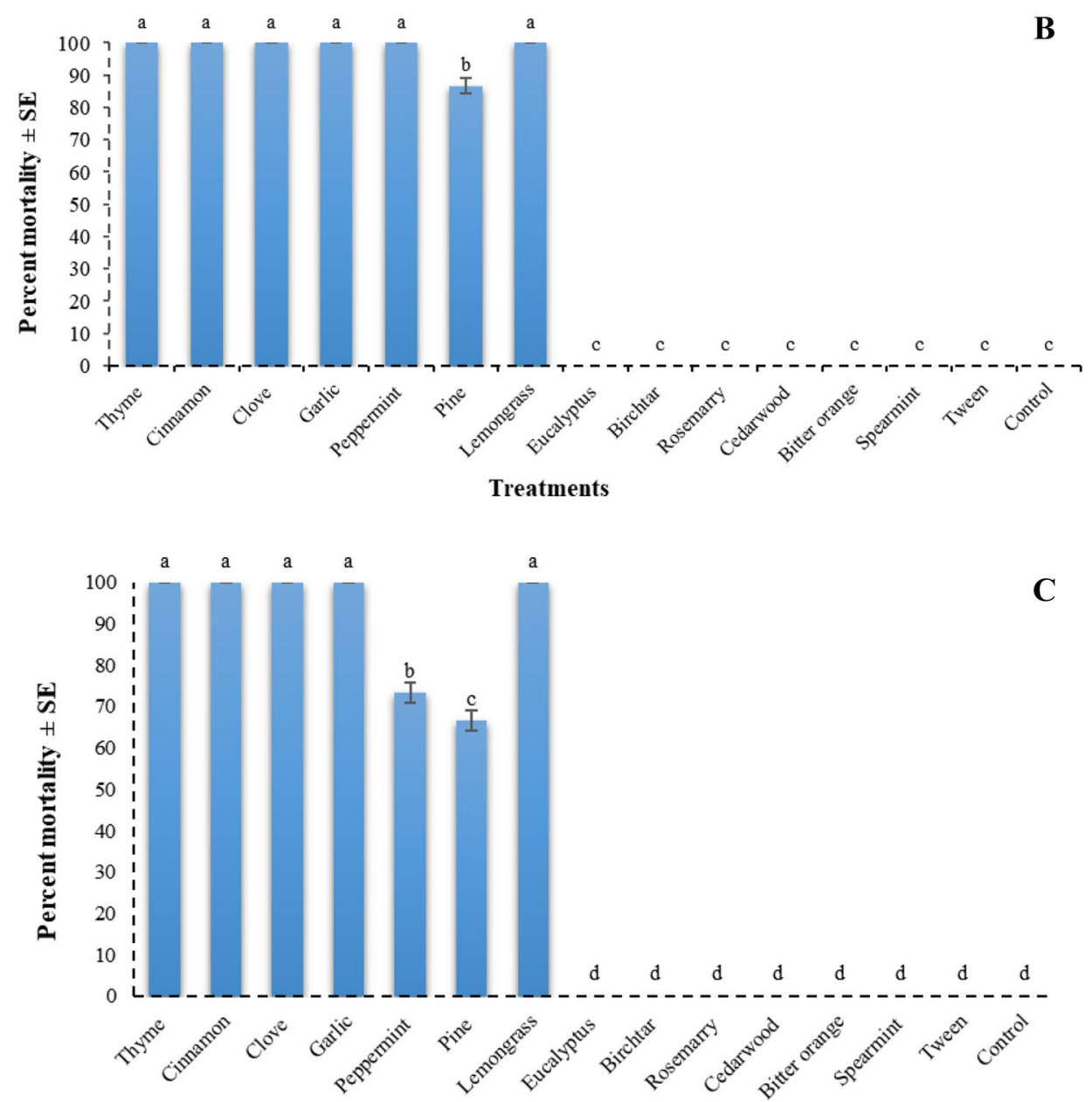

Treatments species $(p<0.01)$ (Fig. 1). Lemongrass caused $100 \%$ mortality in $P$. hermaphrodita and $S$. feltiae while $46.67 \pm 0.15$ percent mortality in H. bacteriophora. However, birch tar, rosemary, cedarwood, bitter orange, spearmint and eucalyptus oil had no significant effect on either nematodes mortality $(P>0.05)$. Pine and peppermint oil caused 53\% and $86 \%, 66 \%$ and $80 \%, 100 \%$ and $73 \%$ mortality in $H$. bacteriophora, S. feltiae and $P$. hermaphrodita after $96 \mathrm{~h}$ of exposure to oil treatment, respectively. 


\section{Behavioural response of nematodes to EOs}

The thrashing assays with all the tested nematode species showed that oil solutions and time both significantly affected nematode behaviour (Figs. 2, 3 and 4) $(p<0.01)$. When nematode species were subjected to different oil solutions, Tween and water, at $0 \mathrm{~s}$, there was no significant difference in the number of thrashes by individual species in most of the tested oils. However, with time, the thrash count of each species was significantly reduced in all the oil solutions. More specifically in cinnamon, clove and garlic oil, no thrash count was recorded after $30 \mathrm{~min}$ and $60 \mathrm{~min}$ of exposure and the nematodes showed an extended form without any movement typical of death (Fig. 5). Further, we observed a significant difference between the number of thrashes of each nematode species exposed to water or Tween at time 0 and $60 \mathrm{~min}(p<0.01)$.



Fig. 2 Mean number of thrashes of H. bacteriophora in 13 EO solutions, Tween 80 control and water control at four different time intervals $(n \pm$ SE). Means followed by the same letter for each oil at four

different time intervals do not differ significantly at $p=0.05$ according to Tukey's multiple comparison test

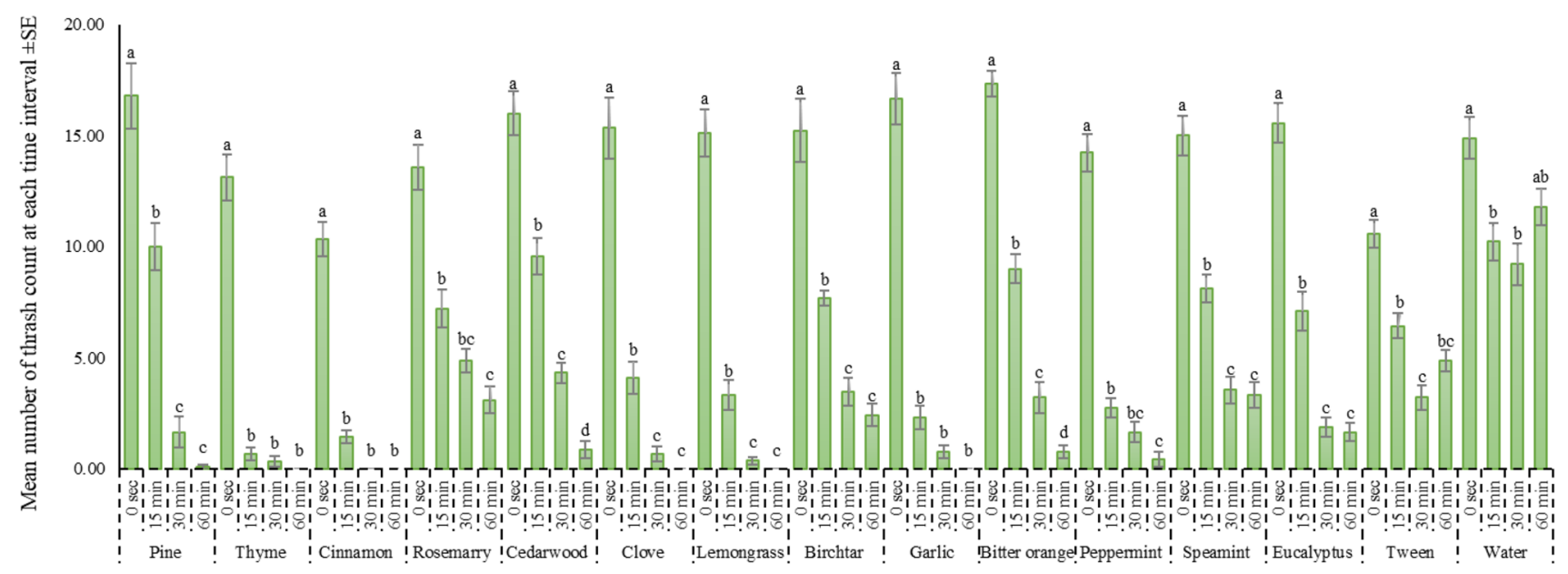

Oil solution at four different time intervals

Fig. 3 Mean number of thrashes of S. feltiae in 13 EO solutions, Tween 80 control and water control at four different time intervals $(n \pm \mathrm{SE})$. Means followed by the same letter for each oil at four dif- ferent time intervals do not differ significantly at $p=0.05$ according to Tukey's multiple comparison test 




Fig. 4 Mean number of thrashes of $P$. hermaphrodita in 13 EO solutions, Tween 80 control and water control at four different time intervals $(n \pm \mathrm{SE})$. Means followed by the same letter for each oil at four different time intervals do not differ significantly at $p=0.05$ according to Tukey's multiple comparison test
Fig. 5 Nematode (H. bacteriophora) in extended and bending form in treatment (thyme) and control, respectively
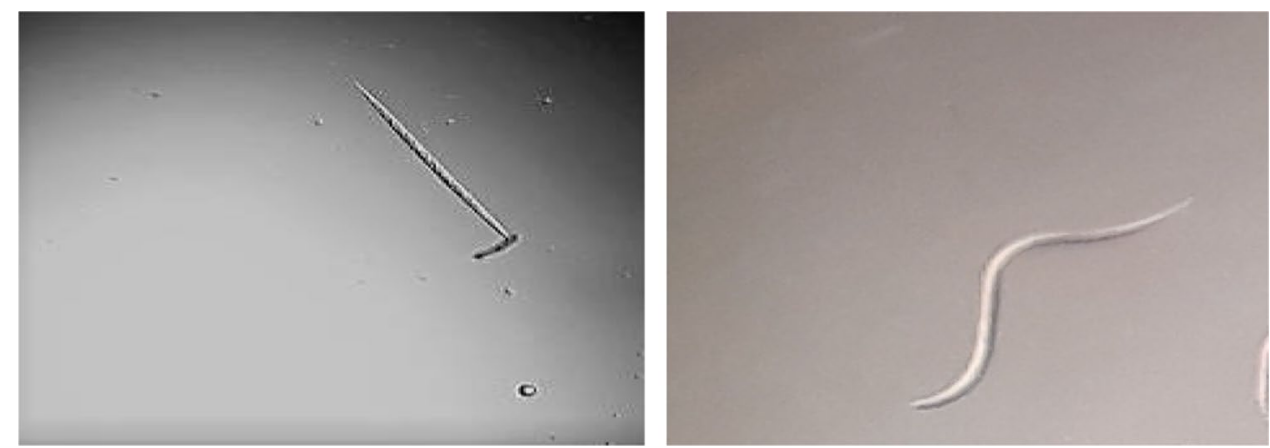

\section{Discussion}

Our results show that among the selected EOs, thyme, cinnamon, clove and garlic oil are highly toxic to the three species of beneficial nematodes studied in this paper. This result is congruous with the findings of other studies (e.g., Pandey and Dwivedi 2000; Chitwood 2002; Park et al. 2005; Meyer et al. 2008; Gupta et al. 2011) that confirmed the toxicity of clove, garlic and cinnamon oil to plant-parasitic nematodes. Thus, thyme, cinnamon, clove and garlic oil not only kill harmful nematodes, they also harm beneficial nematodes. Therefore, serious considerations need to be given when using these oils as a tool in integrated pest management (IPM) programmes that also utilise nematode biological control agents. To date, there has been only a few products available utilising EOs, this is primarily as a result of their expense. One product which is available is Snail \& Slug Away $\AA$, which is based on cinnamon oil as the active ingredient. Another product, which has recently been patented, is ecospray ${ }^{\circledR}$, which uses garlic essential oil.
On the other hand, we find that lemongrass, pine and eucalyptus oil demonstrate different mortality rates to the three species of nematodes. In particular, lemongrass oil is comparatively more toxic to $P$. hermaphrodita and $S$. feltiae than $H$. bacteriophora. Pine oil shows more than 50\% mortality rates in all the three species of nematodes. Eucalyptus oil shows a less toxic effect on all the tested nematodes, i.e. $0 \%$ mortality in $S$. feltiae and $P$. hermaphrodita, and $26.67 \pm 0.15 \%$ mortality in $H$. bacteriophora. Prior study (Gupta et al. 2011) shows that eucalyptus oil at $1000 \mu \mathrm{l} /$ litre causes $80 \%$ mortality in root knot nematode (Meloidogyne incognita) after $3 \mathrm{~h}$ of exposure. Thus, comparing our results with those presented in Gupta et al. (2011), it can be inferred that eucalyptus oil has the clear potential to be used as a biorational pesticide for pest management, because it kills harmful nematodes (even at a lower concentration) but show less toxicity towards beneficial nematodes. The remaining EOs studied in this paper namely, birch tar, cedarwood, rosemary, bitter orange and spearmint oil do not cause the mortality to the nematode species. Thus, our results indicate that these EOs have apparent competence for utilisation in pest 
management as they do not harm the beneficial nematodes, and as previously mentioned these EOs have been reported as effective against harmful nematodes. For instance, Caboni et al. (2013) show that mint species containing carbonyl compounds have a strong and fast-acting effect on the rootknot nematode $M$. incognita.

We observed in most cases that when the mortality is high for one nematode species, it is also usually high for the others and when there is zero mortality for one nematode, it is usually zero for the others. Thus, the nematodes appear to show an "all or nothing" response, i.e. they either all die or all survive with only a small number of oils showing intermediate mortalities. EOs are complex mixture of alcohols, aldehydes, phenol, terpenoids and fatty acid derivatives (Boire et al. 2013). A complete GC-MS analysis of the essential oils used in the present paper is available as Supplementary Material 6 in Klein et al. (2020). Klein et al. sourced their essential oils from the same company that supplied our oils for the present paper. Due to limited resources, nematicidal constituents of the oils were not identified. The insecticidal or nematicidal properties of EOs may be due to the synergistic effect of all its constituents (Oka 2001).

The cuticle of nematodes is a crucial structure for their development and survival. Lipids, which are organic compounds insoluble in water but soluble in solvents like oil, are one of the major components of the nematode cuticle (Page and Johnstone 2007). According to Stadler and Buteler (2009), oils show affinity to the insect and mite body surface, and they penetrate their cuticle and dissolve internal lipids (Taverner et al. 1999). The mortality of nematodes in an oil may be due to the oil's lipophilic properties. Alternatively, the volatile compounds of EOs with nematicidal properties may penetrate through the cuticle of nematodes through diffusion and affect the nervous system. This may help explain nematode mortality by selected EOs. In fact, Najar Rodriguez et al. (2007) show that oils can penetrate the cell membranes and cause disruption of the synaptic transmission of nerve ganglia in insects. However, the mode of action of EOs and their components against nematodes is unclear and needs further investigation.

The lateral movement of nematodes (thrashes per min) signifies an important aspect of locomotion. In our study, we observed that oil solutions have significant effects on nematodes locomotion. The reduction in thrash count of the nematode species may be because either they are paralysed by the oil emulsion or they may be susceptible to different nematicidal constituents of essential oil.

Several plant EOs and phytochemicals are known for their nematicidal activity (Chitwood, 2002). The potential of EOs as biopesticides for harmful nematodes has been examined in many studies (Oka et al. 2000; Tsao and Yu 2000; Gill et al. 2001; Kong et al. 2006; Park et al. 2007; Barbosa et al. 2010; Ntalli et al. 2011; Gupta et al. 2011; Eloh et al. 2019).
In addition, EOs have been tested as an alternative to pesticides on several invertebrates (Isman 2000; Ayvaz et al. 2010) and gastropod pests (Mc Donnell et al. 2016; Sousa et al. 2017; Klein et al. 2020). However, their impact on beneficial nematodes has been completely overlooked and this study raises some important questions on the use of essential oils in IPM programmes. To the best of our knowledge, no study has investigated the toxicity of EOs on beneficial entomopathogenic and slug parasitic nematodes. Furthermore, studying the toxicity of EOs on beneficial nematodes that are naturally present in the environment is important in order to ensure that the use of essential oils do not disturb the balance of the ecosystem.

The findings of this work show that clove, garlic, lemongrass, peppermint and cinnamon oil have the potential to be used as novel nematicides for plant-parasitic nematodes, and they do possess noxious effects on beneficial nematodes like $P$. hermaphrodita, S. feltiae and H. bacteriophora. These nematode species play a significant role in regulating insect and slug pests in the soil (Grewal et al. 2004; Rae et al. 2007), while there are some other EOs (e.g. Spearmint, Rosemary, Eucalyptus [all at $1 \%$ concentration]), which are less toxic to entomopathogenic and slug parasitic nematodes but have potential to kill plant parasitic nematodes like Meloidogyne spp. Therefore, it is important to study the toxicity of different EOs on various beneficial nematodes.

\section{Conclusion}

In a nutshell, the results obtained from the present study could be useful for screening EOs as a biorational pesticide for use in IPM programmes. As the results showed that certain EOs such as cinnamon, clove, garlic, peppermint, lemongrass, thyme, pine and eucalyptus oil are not suitable for the beneficial nematodes and negatively affect their survival and behaviour. These beneficial nematodes are natural enemies to many insect and slug pests in farms and gardens, and conservation of natural enemies of various pests is an important consideration in IPM. Therefore, it is highly recommended to test the EOs on a variety of beneficial organisms and screen out the EOs, which are incompatible with beneficial organisms before they are recommended for pest management programmes. Otherwise, the application of EOs for IPM could act as a double-edged sword.

\section{Author contributions}

RR and CDW conceived the study and planned the experiments. $\mathrm{AB}$ and $\mathrm{K}-\mathrm{LM}-\mathrm{H}$ executed the experiments. $\mathrm{RMcD}$ consulted on methodological issues $A B$ conducted the data analysis under the direction of RR and CDW. AB wrote 
the MS. CDW, RR and RMcD edited the MS. All authors read and agreed to the content of the MS. CDW acted as corresponding author.

Open Access This article is licensed under a Creative Commons Attribution 4.0 International License, which permits use, sharing, adaptation, distribution and reproduction in any medium or format, as long as you give appropriate credit to the original author(s) and the source, provide a link to the Creative Commons licence, and indicate if changes were made. The images or other third party material in this article are included in the article's Creative Commons licence, unless indicated otherwise in a credit line to the material. If material is not included in the article's Creative Commons licence and your intended use is not permitted by statutory regulation or exceeds the permitted use, you will need to obtain permission directly from the copyright holder. To view a copy of this licence, visit http://creativecommons.org/licenses/by/4.0/.

\section{References}

Abbott WS (1925) A method of computing the effectiveness of an insecticide. J econ Entomol 18(2):265-267

Ansari MA, Tirry L, Moens M (2003) Entomopathogenic nematodes and their symbiotic bacteria for the biological control of Hoplia philanthus (Coleoptera: Scarabaeidae). Biol control 28:111-117

Askary TH (2010) Nematodes as biocontrol agents. In: Lichtfouse E (ed) Sociology organic farming climate change and soil Science. Springer, Dordrecht, pp 347-378

Ayvaz A, Sagdic O, Karaborklu S, Ozturk I (2010) Insecticidal activity of the essential oils from different plants against three stored-product insects. J Insect Sci 10:21

Bailey SER (2002) Molluscicidal baits for control of terrestrial gastropods. Molluscs as crop pests 21:33-54

Barbosa P, Lima AS, Vieira P, Dias LS, Tinoco MT, Barroso JG, Pedro LG, Figueiredo AC, Mota M (2010) Nematicidal activity of essential oils and volatiles derived from portuguese aromatic flora against the pinewood nematode, Bursaphelenchus xylophilus. J Nematol 42:8-16

Barua A, Roy S, Handique G, Bora FR, Rahman A, Muraleedharan PDN (2017) clove oil efficacy on the red spider mite, Oligonychus coffeae Nietner (Acari: Tetranychidae) infesting tea plants. Proc Zool Soc Ind 70:92-96

Boire NA, Riedel S, Parrish NM (2013) Essential oils and future antibiotics: new weapons against emerging 'superbugs'. J Anc Dis Prev Rem 1:2

Brattsten LB (1983) Cytochrome P-450 involvement in the interactions between plant terpenes and insect herbivores. In: Hedin PA (ed) Plant resistance to insects. American Chemical Society, pp 173-195

Buckingham SD, Sattelle DB (2009) Fast, automated measurement of nematode swimming (thrashing) without morphometry. BMC Neurosci 10:84

Caboni P, Saba M, Tocco G, Casu L, Murgia A, Maxia A, Menkissoglu-Spiroudi U, Ntalli N (2013) Nematicidal activity of mint aqueous extracts against the root-knot nematode Meloidogyne incognita. J Agr Food Chem 61:9784-9788

Chitwood DJ (2002) Phytochemical based strategies for nematode control. Annu Rev Phytopathol 40:221-249

Coupland J, Abd-Elgawad MM, Askary TH (2017) Beneficial nematodes and the changing scope of crop protection. biocontrol agents: entomopathogenic and slug parasitic nematodes. CABI International, Wallingford, UK, pp 26-42
Ejechi BO, Nwafor OE, Okoko FJ (1999) Growth inhibition of tomato-rot fungi by phenolic acids and essential oil extracts of pepperfruit (Dennetia tripetala). Food Res Int 32:395-399

Eloh K, Kpegba K, Sasanelli N, Koumaglo HK, Caboni P (2019) Nematicidal activity of some essential plant oils from tropical West Africa. Int. J. Pest Manag 66(2):131-141

Gill K, Mehta S, Malik M, Malik O, Walia R (2001) Toxicity of methanolic leaf extracts and essential oils from various plants to the root-knot nematode Meloidogyne incognita. Nematol Mediterr 29:219-222

Grewal PS, Power KT, Grewal SK, Suggars A, Haupricht S (2004) Enhanced consistency in biological control of white grubs (Coleoptera: Scarabaeidae) with new strains of entomopathogenic nematodes. Biol Control 30:73-82

Gupta A, Sharma S, Naik SN (2011) Bio pesticidal value of selected essential oils against pathogenic fungus, termites, and nematodes. Int Biodeter Biodegr 65:703-707

Isman MB (2000) Plant essential oils for pest and disease management. Crop Prot 19:603-608

Klein ML, Chastain TG, Garbacik CJ, Qian YPL, Mc Donnell RJ (2020) Acute toxicity of essential oils to the pest slug Deroceras reticulatum in laboratory and greenhouse bioassays. J Pest Sci 93:415-425

Kong JO, Lee SM, Moon YS, Lee SG, Ahn YJ (2006) Nematicidal activity of plant essential oils against Bursaphelenchus xylophilus (Nematoda: Aphelenchoididae). J Asia Pac Entomol 9:173-178

MacMillan K, Haukeland S, Rae R, Young I, Crawford J, Hapca S, Wilson M (2009) Dispersal patterns and behaviour of the nematode Phasmarhabditis hermaphrodita in mineral soils and organic media. Soil Biol Biochem 41:1483-1490

Mc Donnell R, Yoo J, Patel K, Rios L, Hollingsworth R, Millar J, Paine $\mathrm{T}$ (2016) Can essential oils be used as novel drench treatments for the eggs and juveniles of the pest snail Cornu aspersum in potted plants? J Pest Sci 89:549-555

Meyer SLF, Lakshman DK, Zasada IA, Vinyard BT, Chitwood DJ (2008) Dose-response effects of clove oil from Syzygium aromaticum on the root knot nematode Meloidogyne incognita. Pest Manag Sci 64:223-229

Mossa ATH (2016) Green pesticides: essential oils as biopesticides in insect-pest management. J Environ Sci Technol 9:354-378

Najar-Rodríguez AJ, Walter GH, Mensah RK (2007) The efficacy of a petroleum spray oil against Aphis gossypii glover on cotton. part 1: mortality rates and sources of variation. Pest Manag Sci 63:586-595

Ntalli NG, Ferrari F, Giannakou I, Menkissoglu-Spiroudi U (2011) Synergistic and antagonistic interactions of terpenes against Meloidogyne incognita and the nematicidal activity of essential oils from seven plants indigenous to greece. Pest Manag Sci 67:341-351

Oka Y, Nacar S, Putievsky E, Ravid U, Yaniv Z, Spiegel Y (2000) Nematicidal activity of essential oils and their components against the root-knot nematode. Phytopathol 90:710-715

Oka Y (2001) Nematicidal activity of essential oil components against the root-knot nematode Meloidogyne javanica. Nematol 3:159-164

Page AP, Johnstone IL (2007) The cuticle. WormBook, ed. The C. elegans Research Community, WormBook. https://doi.org/10.1895/ wormbook.1.138.1. http://www.wormbook.org.

Pandey RC, Dwivedi BK (2000) Comparative study of different plant extracts for their nematicidal potential. Current Nematol 11:39-43

Park IK, Kim J, Lee SG, Shin SC (2007) Nematicidal activity of plant essential oils and components from Ajowan (Trachyspermum ammi), Allspice (Pimenta dioica) and Litsea (Litsea cubeba) essential oils against pine wood nematode (Bursaphelenchus xylophilus). J Nematol 39:275-279 
Park IK, Park JY, Kim KH, Choi KS, Choi IH, Kim CS, Shin SC (2005) Nematicidal activity of plant essential oils and components from garlic (Allium sativum) and cinnamon (Cinnamomum verum) oils against the pine wood nematode (Bursaphelenchus xylophilus). Nematol 7:767-774

Perez MP, Navas-Corte's JA, Pascual-Villalobos MJ, Castillo P (2003) Nematicidal activity of EOs and organic amendments from asteraceae against root-knot nematodes. Plant Pathol 52:395-401

Rae R, Verdun C, Grewal PS, Robertson JF, Wilson MJ (2007) Biological control of terrestrial molluscs using Phasmarhabditis hermaphrodita-progress and prospects. Pest Manag Sci 63:1153-1164

Ríos N, Stashenko EE, Duque JE (2017) Evaluation of the insecticidal activity of essential oils and their mixtures against Aedes aegypti (Diptera: culicidae). Rev Bras entomol 61:307-311

Sangwan NK, Verma BS, Verma KK, Dhindsa KS (1990) Nematicidal activity of some essential plant oils. Pestic Sci 28:331-335

Sleigh JN (2010) Functional analysis of nematode nicotinic receptors. Biosci Horiz 3:29-39

Sousa RMOF, Rosa JS, Cunha AC, Fernandes-Ferreira M (2017) Molluscicidal activity of four apiaceae essential oils against the freshwater snail Radix peregra. J Pest Sci 90(3):971-984
Stadler T, Buteler M (2009) Modes of entry of petroleum distilled spray-oils into insects: a review. Bull of Insectol 62(2):169-177

Taverner P, Bailey P, Hodgkinson M, Beattie GAC (1999) Post-harvest disinfestation of lightbrown apple moth, Epiphyas postvittana Walker (Lepidoptera: Tortricidae), with an alkane. J Pestic Sci 55:1159-1166

Tripathi AK, Upadhyay S, Bhuiyan M, Bhattacharya PR (2009) A review on prospects of essential oils as biopesticide in insect-pest management. J Pharmacognosy Phytother 1(5):52-63

Tsao R, Yu Q (2000) Nematicidal activity of monoterpenoid compounds against economically important nematodes in agriculture. J Essent Oil Res 12(3):350-354

Van der Werf HMG (1996) Assessing the impact of pesticides on the environment. Agr Ecosyst Environ 60:81-96

Publisher's Note Springer Nature remains neutral with regard to jurisdictional claims in published maps and institutional affiliations. 